\title{
Accounting for arterial and capillary blood gases for calculation of cerebral blood flow in preterm infants
}

\author{
Silke Brodkorb ${ }^{1} \cdot$ Irina Sidorenko ${ }^{2}$. Varvara Turova ${ }^{3} \cdot$ Esther Rieger-Fackeldey $^{4} \cdot$ Ursula Felderhoff-Müser $^{5}$. \\ Andrey Kovtanyuk ${ }^{3} \cdot$ Renée Lampe ${ }^{3}$ (I)
}

Received: 4 August 2021 / Revised: 14 January 2022 / Accepted: 22 January 2022 / Published online: 12 February 2022

(c) The Author(s) 2022

\begin{abstract}
One of the most feared neurological complications of premature birth is intraventricular hemorrhage, frequently triggered by fluctuations in cerebral blood flow $(\mathrm{CBF})$. Although several techniques for CBF measurement have been developed, they are not part of clinical routine in neonatal intensive care. A promising tool for monitoring of CBF is its numerical assessment using standard clinical parameters such as mean arterial pressure, carbon dioxide partial pressure $\left(\mathrm{pCO}_{2}\right)$ and oxygen partial pressure $\left(\mathrm{pO}_{2}\right)$. A standard blood gas analysis is performed on arterial blood. In neonates, capillary blood is widely used for analysis of blood gas parameters. The purpose of this study was the assessment of differences between arterial and capillary analysis of blood gases and adjustment of the mathematical model for CBF calculation to capillary values. The statistical analysis of $\mathrm{pCO}_{2}$ and $\mathrm{pO}_{2}$ values collected from 254 preterm infants with a gestational age of 23-30 weeks revealed no significant differences between arterial and capillary $\mathrm{pCO}_{2}$ and significantly lower values for capillary $\mathrm{pO}_{2}$. The estimated mean differences between arterial and capillary $\mathrm{pO}_{2}$ of $15.15 \mathrm{mmHg}(2.02 \mathrm{kPa})$ resulted in a significantly higher $\mathrm{CBF}$ calculated for capillary $\mathrm{pO}_{2}$ compared to $\mathrm{CBF}$ calculated for arterial $\mathrm{pO}_{2}$. Two methods for correction of capillary $\mathrm{pO}_{2}$ were proposed and compared, one based on the mean difference and another one based on a regression model.

Conclusion: Capillary blood gas analysis with correction for $\mathrm{pO}_{2}$ as proposed in the present work is an acceptable alternative to arterial sampling for the assessment of $\mathrm{CBF}$.

\section{What is Known:}

- Arterial blood analysis is the gold standard in clinical practice. However, capillary blood is widely used for estimating blood gas parameters.

- There is no significant difference between the arterial and capillary $\mathrm{pCO}_{2}$ values, but the capillary $\mathrm{pO}_{2}$ differs significantly from the arterial one.

What is New:

- The lower capillary $\mathrm{pO}_{2}$ values yield significantly higher values of calculated $\mathrm{CBF}$ compared to $\mathrm{CBF}$ computed from arterial $p \mathrm{O}_{2}$ measurements.

- Two correction methods for the adjustment of capillary $\mathrm{pO}_{2}$ to arterial $\mathrm{pO}_{2}$ that made the difference in the calculated CBF insignificant have been proposed.
\end{abstract}

Keywords Preterm birth · Intraventricular hemorrhage - Cerebral blood flow · Arterial and capillary blood gas analysis . Bland-Altman's plot · Regression model

Communicated by Daniele De Luca

Renée Lampe

renee.lampe@tum.de

1 Department of Neonatology, Munich Clinic Harlaching, Sanatoriumsplatz 2, Munich 81545, Germany

2 Chair of Mathematical Modelling, Mathematical Faculty, Technical University of Munich, Boltzmannstr. 3, Garching 85748, Germany

3 Research Unit for Pediatric Neuroorthopedics and Cerebral Palsy of the Buhl-Strohmaier Foundation, Orthopedic
Department, School of Medicine, Klinikum rechts der Isar, Technical University of Munich, Ismaninger Str. 22, Munich 81675, Germany

4 Department of Pediatrics, School of Medicine, Klinikum rechts der Isar, Technical University of Munich, Ismaninger Str. 22, Munich 81675, Germany

5 Department of Pediatrics I, Neonatology, Pediatric Intensive Care, Pediatric Neurology, University Hospital Essen, University Duisburg-Essen, Hufelandstraße 55, Essen 45147, Germany 


\section{Introduction}

One of the primary concerns in the care for preterm born infants is intraventricular hemorrhage (IVH), which may lead to death or permanent disabilities, such as cerebral palsy, learning disabilities, language disorders, blindness, and seizures. Preterm infants are at higher risk for IVH complications depending on their gestational age, weight, and additional risk factors usually occurring during the first $72 \mathrm{~h}$ of life until postnatal day seven. Infants born before 30 weeks of gestation (WG) or those with a birth weight below $1500 \mathrm{~g}$ are at risk with an overall incidence of 20 to $25 \%[1,2]$. In the preterm brain, IVH typically originates from the highly vascularized area of the germinal matrix $[3,4]$, which is present until $32 \mathrm{WG}$ [5]. This crucial region for physiological fetal brain development contains numerous glial and neuronal precursor cells migrating to the cortex [3, 6]. Originating from the germinal matrix the hemorrhage may expand into the intraventricular space and/or into white and gray matter regions. Hemorrhages usually happen during the first $72 \mathrm{~h}$ of life until postnatal day seven.

Although risk factors of IVH are manifold, there is consensus that the most important ones are perinatal infection or inflammation, reduced coagulation profile, cardiovascular, circulatory and respiratory problems, electrolyte disturbances, mode and site of delivery, time of cord clamping, or genetic factors [6]. Deviations in mean arterial blood pressure (MAP), carbon dioxide pressure $\left(\mathrm{pCO}_{2}\right)$, and cerebral blood flow $(\mathrm{CBF})$ are significant clinical risk factors contributing to the rupture of germinal matrix vessels [7]. Blood gas disturbances in the early postnatal days of life are also suspected to induce brain injury and affect neurological outcome $[8,9]$. Arterial $\mathrm{pCO}_{2}$ is one of the main regulators of $\mathrm{CBF}[10]$. Both hypercarbia and hypocarbia are associated with complications like IVH, periventricular leukomalacia, and bronchopulmonary dysplasia [11]. Furthermore, hypoxia in combination with hypercarbia enforces a decrease in cerebrovascular resistance and a consecutive increase of CBF, which may lead to IVH [12].

Blood gases are usually analyzed in ventilated infants and those with non-invasive respiratory support. Further parameters like bilirubin, blood sugar, lactate, or electrolytes can be obtained from the same sample. There are several methods to get blood samples for gas analysis. Unfortunately, there are neither exact default values nor safe ranges for blood gas interpretation for preterm babies [13, 14]. Arterial blood gas measurements are the gold standard in clinical practice. Very preterm infants mostly receive catheters into the umbilical vessels (artery or vein); hence, arterial blood gas samples are available at least during the first days of life. Venous blood is drawn for, i.e., whole blood counts, coagulation, and liver enzymes. After the catheter is removed, capillary samples and transcutaneous measurements are widely used in order to reduce pain [15-18]. Transcutaneous devices are accurate in estimating gold standard arterial gases in neonatal ARDS (acute respiratory distress syndrome in term or near term born infants). However, due to skin problems (injuries from the transcutaneous device), they are not always available in very preterm infants. For the purpose of this study targeted at the most immature population of preterm infants, we only evaluated routinely taken capillary measurements.

Studies comparing arterial and capillary blood gas analysis in neonates have reported no significant differences for $\mathrm{pCO}_{2}$ in acceptable ranges [19-23]. Differences in $\mathrm{pCO}_{2}$ less than $1 \mathrm{kPa}(0.04-1 \mathrm{kPa})$ are accepted and interpreted as clinically irrelevant [20, 23, 24]. For the other important parameter of our study, oxygen partial pressure $\left(\mathrm{pO}_{2}\right)$, also good correlations have been shown; however, a systematic decrease of capillary $\mathrm{pO}_{2}$ values has been reported [22-25]. Studies measuring the difference between arterial and capillary values revealed clinical significance for a decrease of capillary $\mathrm{pO}_{2}$ in the range 1-3.3 $\mathrm{kPa}[24,25]$. Moreover, several studies have shown that the difference between arterial and capillary $\mathrm{pO}_{2}$ is even more significant for higher $\mathrm{pO}_{2}$ values [20,21, 24].

The purpose of the present study was the statistical comparison of arterial and capillary measurements of $\mathrm{pCO}_{2}$ and $\mathrm{pO}_{2}$ obtained from 254 preterm infants and investigation of their effect on the numerical assessment of CBF. Furthermore, using regression analysis of clinical records two correction methods for the approximation of the arterial $\mathrm{pO}_{2}$ values by $\mathrm{pO}_{2}$ capillary values have been proposed, which allowed us to adjust the mathematical model for CBF calculation to capillary measurements. We demonstrated that following the adjustment, the difference between the CBF values calculated from capillary and arterial measurements was no longer statistically significant.

\section{Materials and methods}

Data were retrospectively obtained from clinical records of 254 preterm infants treated in the Department of Neonatology at the University Hospital Essen and the Department of Pediatrics, School of Medicine, Klinikum rechts der Isar, Technical University of Munich. The study was approved by the ethical committee of the University Hospital Essen, University Duisburg-Essen (Ref. 16-7284-BO) and ethical committee of the School of Medicine, Klinikum rechts der Isar, Technical University of Munich (Ref. 364/15). The gestational age of the sample group ranged from 23 to $30 \mathrm{WG}$ ( $26.45 \pm 2.11 \mathrm{WG}$ ) and the body weight from 335 to $1580 \mathrm{~g}$ $(864.06 \pm 279.10 \mathrm{~g})$. The occurrence of IVH was diagnosed by serial cranial ultrasound examinations. Patients without IVH (118) served as a control group and patients with IVH 
(136) as affected group. Basic clinical characteristics of the cohort are presented in Table 1, in which continuous variables are expressed as mean and standard deviation, while categorical variables are presented as the number of cases and percentages. MAP, $\mathrm{pCO}_{2}$, and $\mathrm{pO}_{2}$ were collected as routine clinical measurements during neonatal care for the first 10 days after birth in the control group, and for up to 7 consecutive days before and 3 days after hemorrhage (average of $6.7 \pm 2.6$ days) in the affected group. Dependent on the clinical situation either arterial or capillary measures were recorded. Capillary measurements were taken by arterialized (heel warmed) standard technique for preterm infants. In our study, arterial blood gas analysis is the gold standard, whereas capillary blood samples were compared to arterial ones. Since medical data were recorded during standard clinical care of the preterm infants, paired arterial and capillary blood measurements were not available. In order to improve the accuracy of statistical estimations and to reduce the influence of the patient's clinical state, we paired consecutive arterial and capillary measurements carried out within several hours (in average $6.7 \pm 4.6 \mathrm{~h}$ ) during neonatal routine care. Measurements that could not be paired were excluded from analysis.

Mathematical evaluation of CBF was done by the hierarchical cerebrovascular model [26] with 19 levels describing different types of vessels (arteries, arterioles, capillaries, venules, and veins). The number and size of vessels on each level were adjusted to gestational age and birth weight of each individual infant [27]. The presence of the germinal matrix was simulated according to the gestational age [28] by the additional parallel compartment on the capillary level [27] with vessel's density and size taken from the literature $[29,30]$. CBF was calculated using Kirchhoff's law as a ratio between cerebral perfusion pressure and total cerebral vascular resistance [31]. The latter was determined from the individual resistances of each vessel with accounting for diameter changes due to the vasoconstriction and vasodilation as a reaction on fluctuations of MAP [31], as well as changes in $\mathrm{pCO}_{2}$ [26] and $\mathrm{pO}_{2}$ [32] estimated from arterial blood samples. Cerebral perfusion pressure was estimated by

Table 1 Basic clinical parameters of the study population

\begin{tabular}{|c|c|c|c|c|}
\hline Parameter & $\begin{array}{l}\text { Whole cohort } \\
254 \\
(100 \%)\end{array}$ & $\begin{array}{l}\text { Control group } \\
118 \\
(100 \%)\end{array}$ & $\begin{array}{l}\text { Affected group } \\
136 \\
(100 \%)\end{array}$ & $p$-value* \\
\hline Gestational age (WG) & $26.5 \pm 2.1$ & $26.7 \pm 2.2$ & $26.3 \pm 2.0$ & 0.1 \\
\hline Birth weight (g) & $864.1 \pm 279.1$ & $850.7 \pm 252.8$ & $875.7 \pm 300.5$ & 0.7 \\
\hline Male & $122(48 \%)$ & $48(40.7 \%)$ & $74(54.4 \%)$ & 0.03 \\
\hline Multiple birth & $95(37.4 \%)$ & $43(36.4 \%)$ & $52(38.2 \%)$ & 0.8 \\
\hline \multirow[t]{3}{*}{ APGAR } & $5.7 \pm 2.2$ & $6.2 \pm 2.0$ & $5.2 \pm 2.2$ & $<0.01$ \\
\hline & $7.1 \pm 1.7$ & $7.5 \pm 1.4$ & $6.8 \pm 1.8$ & $<0.01$ \\
\hline & $8.0 \pm 1.2$ & $8.4 \pm 1.0$ & $7.7 \pm 1.4$ & $<0.01$ \\
\hline Intubation during first 10 days [days] & $4.7 \pm 4.0$ & $3.8 \pm 4.1$ & $5.5 \pm 3.8$ & $<0.01$ \\
\hline $\begin{array}{l}\text { Neonatal bowel perforation (spontaneous/focal intestinal perforation } \\
\text { SIP/FIP) }\end{array}$ & $23(9.1 \%)$ & $3(2.5 \%)$ & $20(14.7 \%)$ & $<0.01$ \\
\hline Metabolic acidosis & $23(9.1 \%)$ & 0 & $23(16.9 \%)$ & $<0.01$ \\
\hline EPH gestosis/preeclampsia & $25(9.8 \%)$ & $18(15.3 \%)$ & $7(5.1 \%)$ & 0.01 \\
\hline Cholestasis & $12(4.7 \%)$ & $1(0.8 \%)$ & $11(8.1 \%)$ & 0.01 \\
\hline Pulmonary hemorrhage & $21(8.3 \%)$ & $5(4.2 \%)$ & $16(11.8 \%)$ & 0.04 \\
\hline Erythrocyte blood transfusion & $164(64.6 \%)$ & $71(60.1 \%)$ & $93(68.4 \%)$ & 0.2 \\
\hline Sepsis & $120(47.2 \%)$ & $50(42.4 \%)$ & $70(51.5 \%)$ & 0.2 \\
\hline Preterm premature rupture of membranes (PPROM) & $73(28.7 \%)$ & $39(33.1 \%)$ & $34(25.0 \%)$ & 0.2 \\
\hline Chorioamnionitis/amniotic infection syndrome & $117(46.1 \%)$ & $50(42.4 \%)$ & $67(49.3 \%)$ & 0.3 \\
\hline Pulmonary stenosis & $4(1.6 \%)$ & $3(2.5 \%)$ & $1(0.7 \%)$ & 0.3 \\
\hline Intrauterine growth retardation (IUGR) & $14(5.5 \%)$ & $8(6.8 \%)$ & $6(4.4 \%)$ & 0.4 \\
\hline Respiratory distress syndrome (RDS) & $84(33.1 \%)$ & $42(35.6 \%)$ & $42(30.9 \%)$ & 0.5 \\
\hline In vitro fertilization (IVF) & $32(12.6 \%)$ & $17(14.4 \%)$ & $15(11.0 \%)$ & 0.5 \\
\hline Disseminated intravascular coagulation (DIC) & $2(0.8 \%)$ & 0 & $2(1.5 \%)$ & 0.5 \\
\hline Respiratory acidosis & $1(0.4 \%)$ & $1(0.8 \%)$ & 0 & 0.5 \\
\hline Necrotizing enterocolitis (NEC) & $20(7.9 \%)$ & $8(6.8 \%)$ & $12(8.8 \%)$ & 0.6 \\
\hline Feto-fetal transfusion syndrome (FFTS) & $8(3.1 \%)$ & $4(3.4 \%)$ & $4(2.9 \%)$ & 1 \\
\hline
\end{tabular}

${ }^{*} p$-values are calculated for difference between control and affected groups 
the difference between clinically measured MAP and intracranial pressure. Since measurement of intracranial pressure is impossible, a constant value of $5 \mathrm{mmHg}$ [33] was used for numerical calculations in all infants.

Statistical comparison of unpaired clinical parameters and calculated CBF was done using the two-sided Wilcoxon's rank-sum test for continuous variables and Fisher's exact test for categorical parameters. In both cases, 5\% significance level was set. For statistical comparison of paired measurements, a paired-sample $t$-test with the same significance level was used. For adjustment of capillary blood measurements, linear regression analysis and Bland-Altman's plot [34-36] were applied. Both methods are widely used in clinical studies $[37,38]$ to assess the agreement and accuracy between two techniques. The basic concept of Bland-Altman's approach is the visualization of the difference of the measurements made by two methods. When differences are symmetrical around zero, there are no systematic bias. The most common way to construct Bland-Altman's plot, when neither of methods is "reference," is plotting the difference between the two paired measurements against their mean value. However, it is also possible to use either of the measurements, reference or actual, instead of their mean value [39]. The present study aimed to approximate arterial values using available capillary values; therefore, the difference between arterial and capillary blood measurements was plotted against the available capillary value. In addition, to estimate the proportional bias, the BlandAltman's analysis was combined with a linear regression analysis $[36,40]$. To assess the significance of the linear regression model, we used $F$-statistic versus constant model with a significance level of 5\%. All statistical methods were taken from the standard MATLAB2020a library.

\section{Results}

In the analyzed data set, the number of arterial and capillary gas measurements depended on gestational age and IVH diagnosis (Table 2). For gestational ages of 23-24 weeks, there were more arterial than capillary blood measurements available, in both the control and the affected group. Starting from $25 \mathrm{WG}$, capillary measurements in the control group dominated over arterial ones, while a dominance of the capillary measurements in the affected group was observed for 30 WG only. Statistical analysis of unpaired arterial and capillary blood measurements revealed that mean values (Fig. 1) significantly differed for $\mathrm{pO}_{2}$, but not for $\mathrm{pCO}_{2}$ (Table 3 ). As a consequence, values of CBF calculated with our model from capillary blood measurements (Fig. 2a) were significantly higher than those calculated from arterial analyses for both control and affected groups (Table 5).

In order to assess the quantitative difference between arterial and capillary $\mathrm{pO}_{2}$ values, we analyzed 293 paired consecutive records collected from both groups (Table 2). The standard scatter plot for capillary $\left(\mathrm{pO}_{2}{ }^{\text {cap }}\right)$ and arterially $\left(\mathrm{pO}_{2}{ }^{\text {art }}\right)$ measurements and corresponding linear regression line are shown in Fig. 3a. Confidence intervals (dotted lines) were calculated as mean \pm 2 standard deviation of $\mathrm{pO}_{2}{ }^{\text {cap }}$ or $\mathrm{pO}_{2}{ }^{\text {art }}$, respectively. Regression line (solid blue line) has a slope of 0.64 and an intercept of $28.32 \mathrm{mmHg}$ $\left(R^{2}=0.1, p<0.001\right)$. The corresponding Bland-Altman plot (Fig. 3b) was constructed as a scatter plot for $\mathrm{pO}_{2}{ }^{\text {cap }}$ and difference $\mathrm{pO}_{2}{ }^{\text {art }}-\mathrm{pO}_{2}{ }^{\text {cap }}$ (black dots). The Bland-Altman plot (Fig. 3b) demonstrated significant differences between capillary and arterial $\mathrm{pO}_{2}$ measurements, which resulted in a systematic bias of $15.15 \mathrm{mmHg}$ (dashed line) (Table 3). As a measure of precision, the $95 \%$ limits of agreement are shown (dotted lines in Fig. 3b). Most of the points are located within the limits of agreement (calculated as mean \pm 2 standard deviation of the difference $\mathrm{pO}_{2}{ }^{\text {art }}-\mathrm{pO}_{2}{ }^{\text {cap }}$ ). All 13 outliers in Fig. $3 b$ are located over the upper limit of agreement and correspond to the outliers of arterial measurements in Fig. 3a, which lie over the upper limit of the confidence interval of $\mathrm{pO}_{2}^{\text {art }}$.

Plotting the differences $\mathrm{pO}_{2}{ }^{\text {art }}-\mathrm{pO}_{2}{ }^{\text {cap }}$ against the capillary measurement $\mathrm{pO}_{2}{ }^{\text {cap }}$ and performing linear regression analysis, we obtained the regression line (black solid line in

Table 2 Number of arterial and capillary blood measurements

\begin{tabular}{|c|c|c|c|c|c|c|}
\hline \multirow{2}{*}{$\begin{array}{l}\text { Weeks of gesta- } \\
\text { tion }\end{array}$} & \multicolumn{3}{|l|}{ No IVH } & \multicolumn{3}{|c|}{ With IVH } \\
\hline & Arterial & Capillary & Paired & Arterial & Capillary & Paired \\
\hline 23 & 164 & 114 & 26 & 293 & 90 & 26 \\
\hline 24 & 327 & 194 & 26 & 315 & 154 & 51 \\
\hline 25 & 139 & 227 & 26 & 272 & 192 & 47 \\
\hline 26 & 104 & 250 & 14 & 291 & 135 & 19 \\
\hline 27 & 89 & 150 & 11 & 119 & 112 & 12 \\
\hline 28 & 11 & 223 & 0 & 162 & 123 & 18 \\
\hline 29 & 8 & 104 & 0 & 105 & 87 & 14 \\
\hline 30 & 0 & 102 & 0 & 6 & 72 & 3 \\
\hline All & 842 & 1364 & 103 & 1563 & 965 & 190 \\
\hline
\end{tabular}



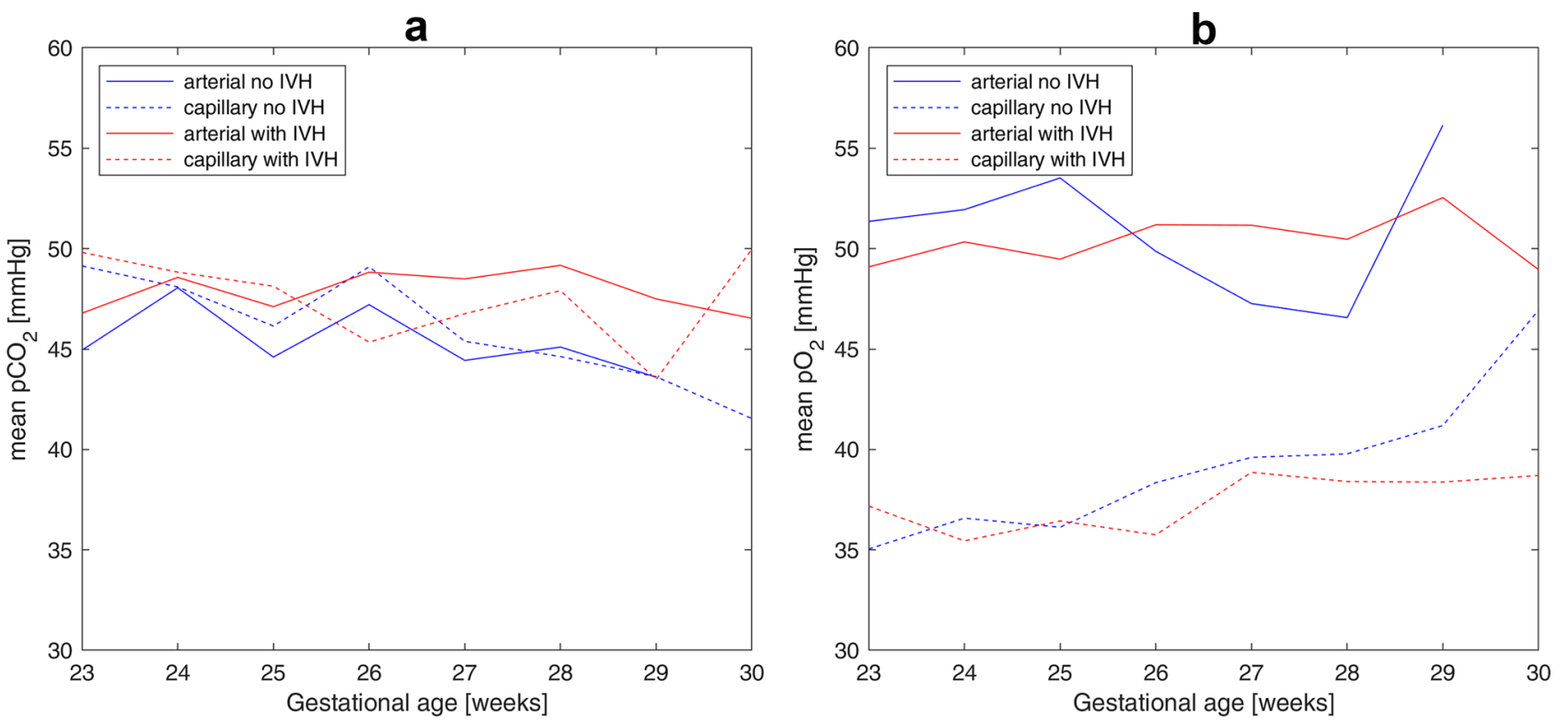

Fig. 1 Mean values of the arterial and capillary blood measurements of $\mathrm{pCO}_{2}(\mathbf{a})$ and $\mathrm{pO}_{2}(\mathbf{b})$ versus gestational age

the Fig. 3b) with statistically significant nonzero intercept and slope (Table 4) indicating the presence of both systematic and proportional bias reflecting statistically significant trend in the data. Systematic bias (Table 4) means that $\mathrm{pO}_{2}$ cap values are consistently lower than $\mathrm{pO}_{2}{ }^{\text {art }}$ values across the whole range of measurement with the mean difference of $15.15 \mathrm{mmHg}$. Negatively proportional bias indicates that the difference between two measuring methods increases with decreasing $\mathrm{pO}_{2}^{\text {cap }}$.

The first approach to adjust capillary data is to add the mean value of difference $\mathrm{pO}_{2}{ }^{\text {art }}-\mathrm{pO}_{2}{ }^{\text {cap }}$ to the measured value: $\mathrm{pO}_{2}{ }^{\mathrm{pM}}=\mathrm{pO}_{2}{ }^{\mathrm{cap}}+15.15 \mathrm{mmHg}$. The resulting corrected values $\mathrm{pO}_{2}{ }^{\mathrm{pM}}$ have the difference $\mathrm{pO}_{2}{ }^{\text {art }}-\mathrm{pO}_{2}{ }^{\mathrm{pM}}$ with arterial measurements (green dots in Fig. 3b) with the mean value of $5.2 \cdot 10^{-15}$. However, the regression line of the difference $\mathrm{pO}_{2}{ }^{\text {art }}-\mathrm{pO}_{2}{ }^{\mathrm{pM}}$ (solid green line in Fig. 3b) still has a nonzero slope and intercept (Table 4), meaning that proportional bias is still present. A better adjustment of capillary measurements can be obtained using linear regression between $\mathrm{pO}_{2}{ }^{\text {cap }}$ and $\mathrm{pO}_{2}{ }^{\text {art }}$ (Fig. 3a) as follows: $\mathrm{pO}_{2}{ }^{\mathrm{pR}}=0.64 \cdot \mathrm{pO}_{2}{ }^{\mathrm{cap}}+28.32 \mathrm{mmHg}$. As a result, the mean difference between $\mathrm{pO}_{2}{ }^{\text {art }}$ and $\mathrm{pO}_{2}{ }^{\mathrm{pR}}$ decreases to zero (Table 4) and mean value of $\mathrm{pO}_{2}$ increases from $36.96 \pm 5.85 \mathrm{mmHg}$ up to $51.97 \pm 3.76 \mathrm{mmHg}$. The estimated mean difference and linear regression coefficients can be further used for the correction of the bias between arterial and capillary measurements in the numerical calculation of $\mathrm{CBF}$.

The CBF values calculated for arterial, capillary, and corrected capillary values are compared in Table 5. Since our statistical analysis revealed no significant differences between arterial and capillary blood measurements for $\mathrm{pCO}_{2}$ (Table 3), the estimated for $\mathrm{pCO}_{2}$ mean difference of $-0.51 \mathrm{mmHg}(-0.07 \mathrm{kPa})$ was neglected when calculating CBF. Correction of capillary $\mathrm{pO}_{2}$ was carried out using three methods: (1) with mean value of unpaired measurements, $\mathrm{pO}_{2}{ }^{\mathrm{upM}}=\mathrm{pO}_{2}{ }^{\text {cap }}+12.63 \mathrm{mmHg}$ (correction I); (2) with mean value of paired measurements: $\mathrm{pO}_{2}{ }^{\mathrm{pM}}=\mathrm{pO}_{2}{ }^{\mathrm{cap}}+15.15 \mathrm{mmHg}$ (correction II); and (3) with linear regression coefficients: $\mathrm{pO}_{2}{ }^{\mathrm{pR}}=0.64 \cdot \mathrm{pO}_{2}{ }^{\mathrm{cap}}+28.32 \mathrm{mmHg}$ (correction III). After correction, the difference between CBF calculated from arterial and capillary measurements (Fig. 2b) was no longer significant both in control and affected groups ( $p_{a}$-values in Table 5). Furthermore, the difference between correction methods was also not significant in both groups ( $p_{\text {dif }}$-values in Table 5). Although the difference between mean values of $\mathrm{CBF}$ in control and affected groups was higher for arterial measurements than for capillary ones (both uncorrected and corrected), it was insignificant for all kinds of $\mathrm{pO}_{2}$ values $\left(p_{\mathrm{IVH}}\right.$-values in Table 5).

\section{Discussion}

The main goal in the treatment of preterm infants is to avoid cerebral hemorrhage and its neurological consequences. $\mathrm{CBF}$ plays a significant role in the development of IVH, but is still not routinely measured during neonatal clinical care of preterm infants. Therefore, the aim of the present study was to adjust a mathematical model for CBF calculation for data obtained by regular analysis from arterial and 


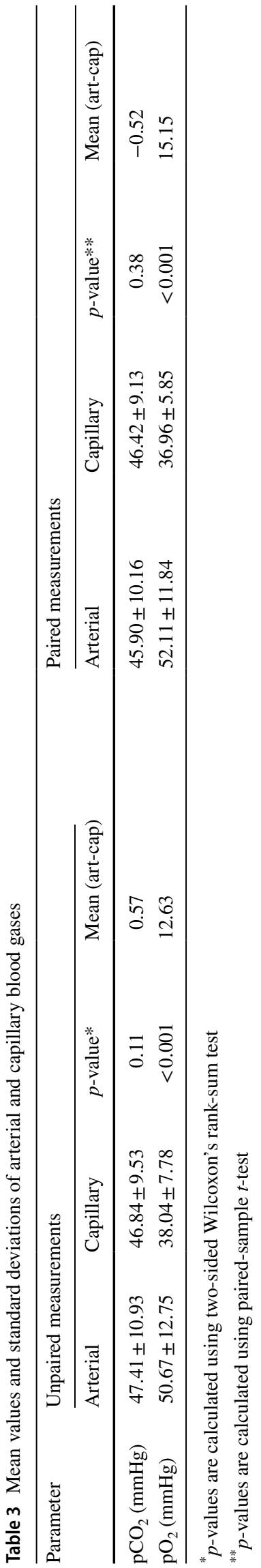

capillary blood gas samples. Linear regression analysis and Bland-Altman's plot were used to assess the correspondence between the two methods of blood sampling. Statistical analyses of clinical records of 254 preterm infants revealed no significant differences between the values of $\mathrm{pCO}_{2}$ obtained from arterial or capillary blood samples, what is in agreement with previous findings $[20,22,25]$ that capillary blood measurements of $\mathrm{pCO}_{2}$ correctly predict arterial values. Likewise, Tan [41] has confirmed that except for $\mathrm{pO}_{2}$ venous and capillary blood gases in neonates are well correlated and mostly interchangeable with arterial values.

In the present data set, capillary $\mathrm{pO}_{2}$ values were significantly lower than arterial ones and CBF values calculated from the capillary $\mathrm{pO}_{2}$ were significantly higher than that computed from arterial $\mathrm{pO}_{2}$. This is in agreement with previous observations $[42,43]$ that due to the cerebral autoregulation, a decrease in $\mathrm{pO}_{2}$ leads to vasodilation and, as a consequence, to a linear increase in CBF. To adjust capillary measurements to arterial ones, statistical analysis was performed in two ways: for unpaired and paired measurements. In both cases, capillary blood analyses of $\mathrm{pO}_{2}$ showed systematic and proportional bias in comparison to arterial ones. It is important to underline that the mean difference between arterial and capillary $\mathrm{pO}_{2}$ was similar in both approaches, namely, 12.63 for unpaired data and 15.15 for paired data. The estimated mean difference of $15.15 \mathrm{mmHg}(2.03 \mathrm{kPa})$ was close to published discrepancies of $2.17 \mathrm{kPa}(16.28 \mathrm{mmHg})$ and $2.47 \mathrm{kPa}$ $(18.53 \mathrm{mmHg})$ evaluated from 158 paired arterial and capillary blood samples being obtained from warmed and not warmed heels, respectively [24]. However, these values are lower than the difference of $30.2 \mathrm{mmHg}(4.03 \mathrm{kPa})$ estimated from capillary blood samples drawn from 21 preterm infants using the Tenderfoot automated capillary sampling device [22]. The estimated mean difference between capillary and arterial $\mathrm{pO}_{2}$ values was added to the capillary $\mathrm{pO}_{2}$ measurement. Two corrections, $\mathrm{pO}_{2}{ }^{\text {upM }}$ obtained from unpaired measurements and $\mathrm{pO}_{2}{ }^{\mathrm{pM}}$ obtained from paired measurements, have reduced systematic bias, but not the proportional one. A better adjustment was obtained using correction with linear regression coefficients. We assumed that paired measurements are more reliable than unpaired ones and for this reason used paired measurements for regression analyses. The correction $\mathrm{pO}_{2}{ }^{\mathrm{pR}}$ compensated both systematic and proportional bias for differences between capillary and arterial $\mathrm{pO}_{2}$.

Three correction methods were used in the mathematical calculation of $\mathrm{CBF}$, and the difference between results was insignificant. Mean CBF values calculated using $\mathrm{pO}_{2}{ }^{\mathrm{upM}}$, $\mathrm{pO}_{2}{ }^{\mathrm{pM}}$, and $\mathrm{pO}_{2}{ }^{\mathrm{pR}}$ were decreased in comparison to that computed using uncorrected capillary $\mathrm{pO}_{2}$ values. The difference between CBF calculated using arterial and corrected capillary $\mathrm{pO}_{2}$ was proven to be statistically insignificant. Thus, the 
a

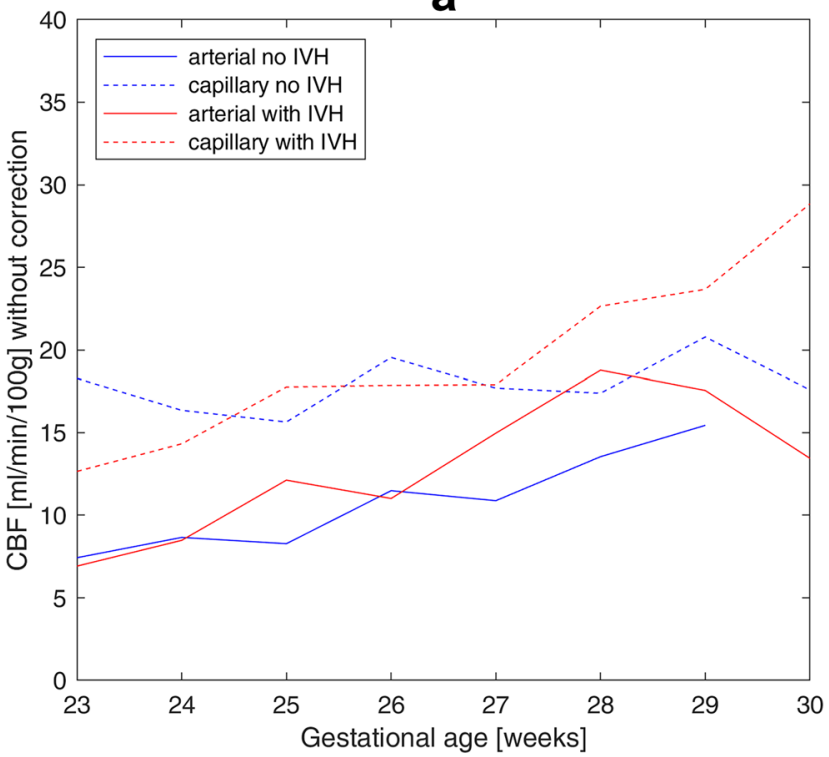

Fig. 2 Mean values of CBF calculated from arterial (solid lines) and capillary (dashed lines) blood measurements versus gestational age: a capillary $\mathrm{pO}_{2}$ values without correction; b capillary $\mathrm{pO}_{2}$ meas-

artificial increase of calculated CBF due to the uncorrected capillary $\mathrm{pO}_{2}$ has been compensated by the proposed statistical correction methods. The comparison of CBF between control and affected groups revealed that CBF was insignificantly higher in the affected group both for arterial and capillary (uncorrected and corrected) $\mathrm{pO}_{2}$.

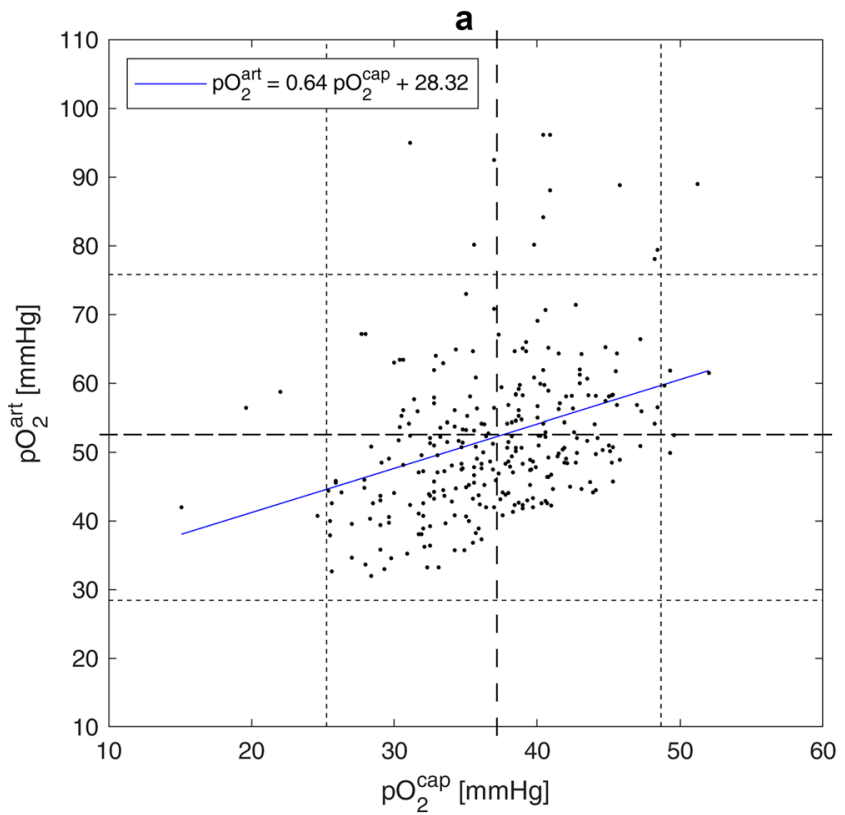

Fig. 3 a Scatter plot for capillary and arterial measurements of $\mathrm{pO}_{2}$. Dashed and dotted lines indicate mean and mean \pm 2 standard deviation of variables on the corresponding axis. b Bland-Altman plot for

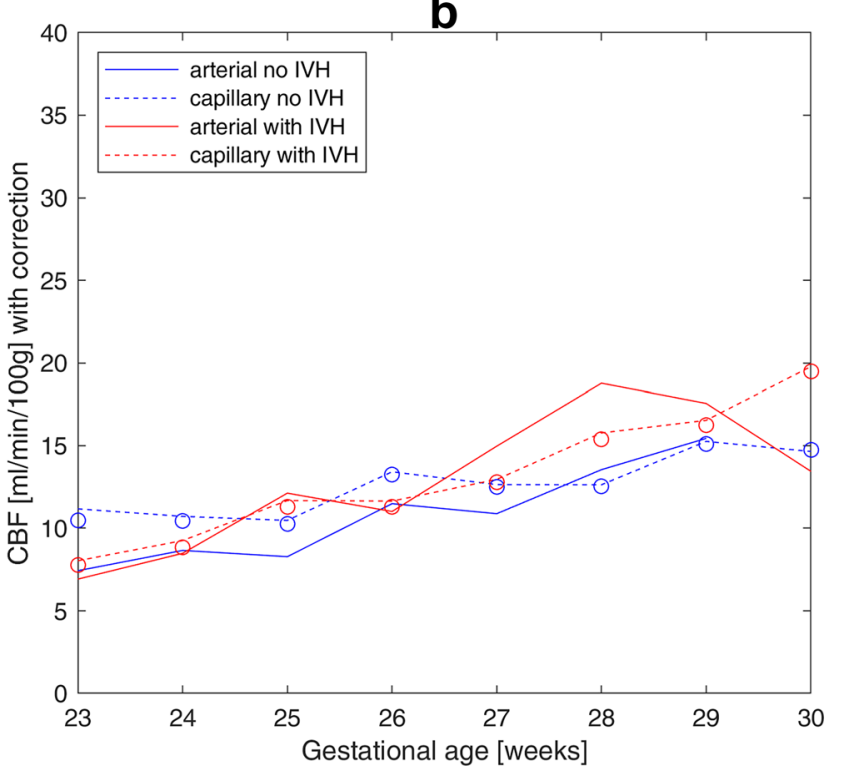

urements corrected with mean difference (dashed lines without symbols: $\mathrm{pO}_{2}{ }^{\text {cap }}+15.15 \mathrm{mmHg}$ ) or with linear regression (circles: 0.64. $\mathrm{pO}_{2}{ }^{\mathrm{cap}}+28.32 \mathrm{mmHg}$ )

Although the regression model was superior in reduction of bias, all correction methods have resulted in statistically equal $\mathrm{CBF}$ values calculated from arterial and corrected capillary measurements, with no significant difference between correction methods. Thus, the correction $\mathrm{pO}_{2}{ }^{\mathrm{pR}}$ can be proposed for mathematical calculation of CBF, while the correction $\mathrm{pO}_{2}{ }^{\mathrm{pM}}$

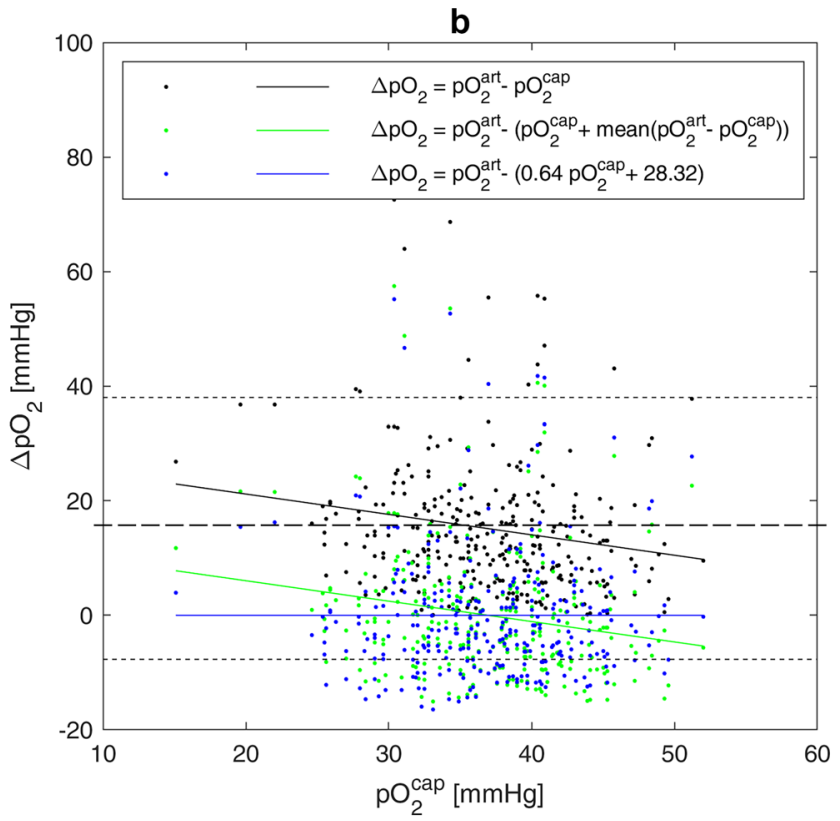

the difference between capillary and arterial measurements of $\mathrm{pO}_{2}$. Dashed and dotted lines indicate mean difference and $95 \%$ limits of agreement for the difference $\mathrm{pO}_{2}{ }^{\text {art }}-\mathrm{pO}_{2}{ }^{\text {cap }}$ 
Table 4 The difference between arterial and capillary measurements of $\mathrm{pO}_{2}$ using linear regression models

\begin{tabular}{lllll}
\hline Difference $(\mathrm{mmHg})$ & Mean $(\mathrm{mmHg})$ & Intercept $(\mathrm{mmHg})$ & Slope & $p$-value* \\
\hline $\mathrm{pO}_{2}{ }^{\text {art }}-\mathrm{pO}_{2}{ }^{\text {cap }}$ & 15.15 & 28.32 & -0.36 & 0.002 \\
$\mathrm{pO}_{2}{ }^{\text {art }}-\mathrm{pO}_{2}{ }^{\mathrm{pM}}$ & $5.2 \cdot 10^{-15}$ & 13.17 & -0.36 & 0.002 \\
$\mathrm{pO}_{2}{ }^{\text {art }}-\mathrm{pO}_{2}{ }^{\mathrm{pR}}$ & $-4 \cdot 10^{-16}$ & $-1 \cdot 10^{-14}$ & $2 \cdot 10^{-16}$ & 1 \\
\hline
\end{tabular}

${ }^{*} p$-values are calculated using $F$-statistic versus constant model can be suggested as a simple and convenient approximation of arterial measurement for practical application.

\section{Limitations of the study}

The most important limitations of the present study arose from its retrospective nature. Medical records were evaluated in two different hospitals over a period of 10 years. During this time, the blood sampling technique and arterialization process may have changed, although its effect on capillary measurements is still under debate [24, 25]. In order to minimize the effects of data collection methods, arterial and capillary measurements from the same patient were analyzed. The main disadvantage was the lack of paired blood gas measurements. Pairs of arterial and capillary measurements were formed from the successive records of clinical routine data. As a consequence, time intervals between measurements were up to several hours, which could increase estimated errors. However, statistical values obtained from 4734 unpaired measurements were close to those of paired measurements. Besides, 293 pairs of measurements from 254 infants analyzed in the current study clearly outnumbered data sets from pervious clinical studies in 21 [22] or 41 [24] preterm infants.

Another limitation of the study was the lack of a comparison between calculated and measured values of CBF. Although near infrared spectroscopy (NIRS) and Doppler ultrasound are available in modern neonatal intensive care units to evaluate cerebral perfusion, their use is dependent on special clinical situations. Doppler ultrasound is used in critically ill infants (i.e., following severe intracerebral hemorrhage or for exclusion of cerebral edema). NIRS is used mainly for research purposes and for special clinical situations such as asphyxia in term born infants.

The main purpose of the present study was the adjustment of the mathematical model for CBF calculation to capillary measurements. Since other clinical parameters such as oxygen saturation $\mathrm{SO}_{2}, \mathrm{pH}$, hematocrit, thrombocyte count, and indicators of inflammation are not yet included in this model, they were not analyzed. It is planned to account for them in further extensions of the mathematical model.
Table 5 Mean values and standard deviations of CBF calculated from arterial and capillary blood measurements without and with correction of capillary $\mathrm{pO}_{2}$. The $p_{a}$-values* are calculated versus $\mathrm{CBF}$ computed using $\mathrm{pO}_{2}{ }^{\text {art }}$. The $p_{\text {IVH }^{-v a l u e s}} *$ are calculated for the difference between control and affected groups. The $p_{\text {dif }^{-}}$ values* are calculated for the difference in correction methods

\begin{tabular}{|c|c|c|c|}
\hline $\mathrm{pO}_{2}(\mathrm{mmHg})$ & $\begin{array}{l}\text { CBF }(\mathrm{ml} / 100 \mathrm{~g} / \mathrm{min}) \\
\text { No IVH }\end{array}$ & $\begin{array}{l}\text { CBF (ml/100 g/min) } \\
\text { With IVH }\end{array}$ & $p_{\text {IVH }}$ \\
\hline $\mathrm{pO}_{2}^{\text {art }}$ & $8.99 \pm 4.61$ & $11.42 \pm 9.33$ & 0.39 \\
\hline $\mathrm{pO}_{2}{ }^{\mathrm{cap}}$ (no correction) & $\begin{array}{l}17.76 \pm 8.76 \\
p_{a}<0.001\end{array}$ & $\begin{array}{l}18.76 \pm 11.18 \\
p_{a}=0.02\end{array}$ & 0.51 \\
\hline $\mathrm{pO}_{2}{ }^{\mathrm{upM}}$ (correction I) & $\begin{array}{l}12.82 \pm 5.57 \\
p_{a}=0.15\end{array}$ & $\begin{array}{l}13.13 \pm 7.19 \\
p_{a}=0.79\end{array}$ & 0.79 \\
\hline $\mathrm{pO}_{2}{ }^{\mathrm{pM}}$ (correction II $)$ & $\begin{array}{l}12.43 \pm 5.29 \\
p_{a}=0.34 \\
p_{\mathrm{dif}}=0.58(\text { corrections II and I) }\end{array}$ & $\begin{array}{l}12.65 \pm 6.79 \\
p_{a}=0.96 \\
p_{\text {dif }}=0.65(\text { corrections II and I })\end{array}$ & 0.79 \\
\hline $\mathrm{pO}_{2}{ }^{\mathrm{pR}}$ (correction III) & $\begin{array}{l}12.24 \pm 5.06 \\
p_{a}=0.39 \\
p_{\text {dif }}=0.44 \text { (corrections III and I) } \\
p_{\text {dif }}=0.57 \text { (corrections III and II) }\end{array}$ & $\begin{array}{l}12.32 \pm 6.45 \\
\mathrm{p}_{\mathrm{a}}=0.96 \\
p_{\text {dif }}=0.57 \text { (corrections III and I) } \\
p_{\text {dif }}=0.65 \text { (corrections III and II) }\end{array}$ & 0.79 \\
\hline
\end{tabular}

${ }^{*} p_{a}, p_{\mathrm{IVH}}$, and $p_{\mathrm{dif}}$ values are calculated using two-sided Wilcoxon's rank-sum test 


\section{Conclusion}

The present study has compared arterial and capillary blood gas analysis, investigated the effect of capillary measurements of $\mathrm{pCO}_{2}$ and $\mathrm{pO}_{2}$ on calculated $\mathrm{CBF}$, and adjusted the mathematical model for CBF calculation to capillary blood analyses. Following the adjustment, the difference between CBF values calculated from capillary and arterial samples became statistically insignificant. Therefore, we state that capillary blood analyses with correction for $\mathrm{pO}_{2}$ as proposed in the present work is an acceptable alternative to arterial sampling for assessment of CBF. Thus, this mathematical model may help to predict critical CBF values allowing early identification of preterm infants at risk for IVH.

Abbreviations CBF: Cerebral blood flow; IVH: Intraventricular cerebral hemorrhage; MAP: Mean arterial pressure; $\mathrm{pCO}_{2}$ : Carbon dioxide partial pressure; $\mathrm{pO}_{2}$ : Oxygen partial pressure; WG: Week of gestation

Acknowledgements The last author appreciates the Markus Würth Professorship at the Technical University of Munich.

Authors' contributions SB: data analysis and interpretation, manuscript drafting; IS: model development, numerical simulations, statistical data analysis and interpretation, manuscript drafting, main revision; VT: model development, numerical simulations, statistical data analysis and interpretation, manuscript drafting, main revision; ER-F: data collection, data analysis and interpretation, manuscript drafting; UF-M: data collection, data analysis and interpretation, manuscript drafting; AK: model development, numerical simulations; RL: supervising, model development, data analysis and interpretation, manuscript drafting.

Funding Open Access funding enabled and organized by Projekt DEAL. This study was funded by the Klaus Tschira Foundation, Würth Foundation, and Buhl-Strohmaier-Foundation.

Availability of data and material The dataset supporting the conclusions of this article is available at the mediaTUM, publications repository of the Technical University of Munich, https://mediatum.ub.tum. de/1521896.

Code availability All calculations presented in the paper were produced with the standard software package MATLAB2020a.

\section{Declarations}

Ethical approval The study was approved by the ethic committee of School of Medicine, Klinikum rechts der Isar, Technical University of Munich (Ref. 364/15) and the ethic committee of University Hospital Essen, University Duisburg-Essen (Ref. 16-7284-BO).

Consent to participate According to the rules of the Ethic Committees of the University Hospital of the Technical University of Munich and of the University Hospital Essen of the University Duisburg-Essen, no informed consent from parents was necessary for retrospective data from the existing medical files.

Consent for publication According to the rules of the Ethic Committees of the University Hospital of the Technical University of Munich and of the University Hospital Essen of the University Duisburg-Essen, no informed consent from parents was necessary for retrospective data from the existing medical files.

Conflict of interest The authors declare no competing interests.

Open Access This article is licensed under a Creative Commons Attribution 4.0 International License, which permits use, sharing, adaptation, distribution and reproduction in any medium or format, as long as you give appropriate credit to the original author(s) and the source, provide a link to the Creative Commons licence, and indicate if changes were made. The images or other third party material in this article are included in the article's Creative Commons licence, unless indicated otherwise in a credit line to the material. If material is not included in the article's Creative Commons licence and your intended use is not permitted by statutory regulation or exceeds the permitted use, you will need to obtain permission directly from the copyright holder. To view a copy of this licence, visit http://creativecommons.org/licenses/by/4.0/.

\section{References}

1. Crump C, Sundquist K, Sundquist J, Winkleby MA (2011) Gestational age at birth and mortality in young adulthood. JAMA 306:1233-1240. https://doi.org/10.1001/jama.2011.1331

2. Schmid MB, Reister F, Mayer B, Hopfner RJ, Fuchs H, Hummler HD (2013) Prospective risk factor monitoring reduces intracranial hemorrhage rates in preterm infants. Dtsch Arztebl Int 110:489 496. https://doi.org/10.3238/arztebl.2013.0489

3. Ballabh $P$ (2010) Intraventricular hemorrhage in premature infants: mechanism of disease. Pediatr Res 67:1-8. https://doi. org/10.1203/PDR.0b013e3181c1b176

4. Sidorenko I, Turova V, Botkin N, Kovtanyuk A, Eckardt L, AlvesPinto A, Lampe R (2020) Assessing haemorrhage-critical values of cerebral blood flow by modelling biomechanical stresses on capillaries in the immature brain. Sci Rep 10:14196. https://doi. org/10.1038/s41598-020-71087-7

5. Whitelaw A (2012) Periventricular hemorrhage: a problem still today. Early Hum Dev 88:965-969. https://doi.org/10.1016/j.earlhumdev. 2012.09.004

6. Leijser LM, de Vries LS (2019) Preterm brain injury: Germinal matrix-intraventricular hemorrhage and post-hemorrhagic ventricular dilatation. Handb Clin Neurol 162:173-199. https://doi. org/10.1016/B978-0-444-64029-1.00008-4

7. Lampe R, Rieger-Fackeldey E, Sidorenko I, Turova V, Botkin N, Eckardt L, Felderhoff-Müser U (2020) Assessing key clinical parameters before and after intraventricular hemorrhage in very preterm infants. Eur J Pediatr 179:929-937. https://doi.org/10. 1007/s00431-020-03585-9

8. Leviton A, Allred E, Kuban KCK, Dammann O, O'Shea TM, Hirtz D, Schreiber MD, Paneth N (2010) Early blood gas abnormalities and the preterm brain. Am J Epidemiol 172:907-916. https://doi.org/10.1093/aje/kwq222

9. Leviton A, Allred EN, Joseph RM, O'Shea TM, Kuban KCK (2017) Newborn blood gas derangements of children born extremely preterm and neurocognitive dysfunctions at age 10 years. Respir Physiol Neurobiol 242:66-72. https://doi.org/10. 1016/j.resp.2017.04.002

10. Ambalavanan N, Carlo WA (2001) Hypocapnia and hypercapnia in respiratory management of newborn infants. Clin Perinatol 28:517-531. https://doi.org/10.1016/s0095-5108(05)70104-4

11. Erickson SJ, Grauaug A, Gurrin L, Swaminathan M (2002) Hypocarbia in the ventilated preterm infant and its effect on intraventricular haemorrhage and bronchopulmonary dysplasia. 
J Paediatr Child Health 38:560-562. https://doi.org/10.1046/j. 1440-1754.2002.00041.x

12. van Bel F, van de Bor M, Baan J, Ruys JH (1988) The influence of abnormal blood gases on cerebral blood flow velocity in the preterm newborn. Neuropediatrics 19:27-32. https://doi.org/10. 1055/s-2008-1052397

13. Huang H, Cheung PY, O'Reilly M, van Os S, Solevag AL, Aziz K, Schmolzer GM (2017) Impact of changing clinical practices on early blood gas analyses in very preterm infants and their associated inpatient outcomes. Front Pediatr 5:11. https://doi. org/10.3389/fped.2017.00011

14. Wong SK, Chim M, Allen J, Butler A, Tyrrell J, Hurley T, Molloy EJ (2021) Carbon dioxide levels in neonates: what are safe parameters? Pediatr Res 2021:1-8. https://doi.org/10.1038/ s41390-021-01473-y

15. Paes B, Janes M, Vegh P, LaDuca F, Andrew M (1993) A comparative study of heel-stick devices for infant blood collection. Am J Dis Child 147:346-348. https://doi.org/10.1001/archpedi. 1993.02160270108032

16. Dar K, Williams T, Aitken R, Woods KL, Fletcher S (1995) Arterial versus capillary sampling for analysing blood gas pressures. BMJ 310:24-25. https://doi.org/10.1136/bmj.310.6971. 24

17. Janes M, Pinelli J, Landry S, Downey S, Paes B (2002) Comparison of capillary blood sampling using an automated incision device with and without warming the heel. J Perinatol 22:154158. https://doi.org/10.1038/sj.jp.7210583

18. Folk LA (2007) Guide to capillary heelstick blood sampling in infants. Adv Neonatal Care 7(4):171-178. https://doi.org/10. 1097/01.anc.0000286333.67928.04

19. Desai SD, Holloway R, Thambiran AK, Wesley AG (1967) A comparison between arterial and arterialized capillary blood in infants. S Afr Med J 41:13-15. (PMID: 6017383)

20. Harrison AM, Lynch JM, Dean JM, Witte MK (1997) Comparison of simultaneously obtained arterial and capillary blood gases in pediatric intensive care unit patients. Crit Care Med 25:19041908. https://doi.org/10.1097/00003246-199711000-00032

21. Hunt CE (1973) Capillary blood sampling in the infant: usefulness and limitations of two methods of sampling, compared with arterial blood. Pediatrics 51:501-506. (PMID: 4707867)

22. Johnson K, Cress G, Connolly N, Burmeister L, Widness J (2000) Neonatal laboratory blood sampling: comparison of results from arterial catheters with those from an automated capillary device. Neonatal Netw 19:27-34. https://doi.org/10. 1891/0730-0832.19.1.27

23. Yang KC, Su BH, Tsai FJ, Peng CT (2002) The comparison between capillary blood sampling and arterial blood sampling in an NICU. Acta Paediatr Taiwan 43:124-126. (PMID: 12148960)

24. McLain BI, Evans J, Dear PR (1988) Comparison of capillary and arterial blood gas measurements in neonates. Arch Dis Child 63:743-747. https://doi.org/10.1136/adc.63.7_spec_no. 743

25. Higgins C (2008) Capillary blood gases: to arterialize or not. MLO Med Lab Obs 40:4-7. (PMID: 19065944)

26. Piechnik SK, Chiarelli PA, Jezzard P (2008) Modelling vascular reactivity to investigate the basis of the relationship between cerebral blood volume and flow under $\mathrm{CO} 2$ manipulation. Neuroimage 39:107-118. https://doi.org/10.1016/j.neuroimage. 2007.08.022

27. Sidorenko I, Turova V, Botkin N, Eckardt L, Alves-Pinto A, Felderhoff-Müser U, Rieger-Fackeldey E, Kovtanyuk A, Lampe R (2018) Modeling cerebral blood flow dependence on carbon dioxide and mean arterial blood pressure in the immature brain with accounting for the germinal matrix. Front Neurol 9:812. https://doi.org/10.3389/fneur.2018.00812

28. Kinoshita Y, Okudera T, Tsuru E, Yokota A (2001) Volumetric analysis of the germinal matrix and lateral ventricles performed using MR images of postmortem fetuses. Am J Neuroradiol 22:382-388. http://www.ncbi.nlm.nih.gov/pmc/articles/pmc7973932/

29. Trommer BL, Groothuis DR, Pasternak JF (1987) Quantitative analysis of cerebral vessels in the newborn puppy: the structure of germinal matrix vessels may predispose to hemorrhage. Pediatr Res 22:23-28. https://doi.org/10.1203/00006450-198707000-00007

30. Ballabh P, Braun A, Nedergaard M (2004) Anatomic analysis of blood vessels in germinal matrix, cerebral cortex, and white matter in developing infants. Pediatr Res 56:117-124. https:// doi.org/10.1203/01.pdr.0000130472.30874.ff

31. Lampe R, Botkin N, Turova V, Blumenstein T, Alves-Pinto A (2014) Mathematical modelling of cerebral blood circulation and cerebral autoregulation: towards preventing intracranial hemorrhages in preterm newborns. Comput Math Methods Med 2014:965275. https://doi.org/10.1155/2014/965275

32. Sidorenko I, Turova V, Kovtanyuk A, Lampe R (2020) The numerical assessment of cerebral blood flow in immature brain of preterm infants. CEUR Workshop Proceedings 22783:199_ 207. http://ceur-ws.org/Vol-2783/paper15.pdf

33. Easa D, Tran A, Bingham W (1983) Noninvasive intracranial pressure measurement in the newborn: an alternate method. Am J Dis Child 137:332-335. https://doi.org/10.1001/archpedi.1983.02140300014004

34. Bland JM, Altman DG (1986) Statistical methods for assessing agreement between two methods of clinical measurement. Lancet 1:307-310. (PMID: 2868172)

35. Bland JM, Altman DG (1999) Measuring agreement in method comparison studies. Stat Methods Med Res 8:135-160. https:// doi.org/10.1191/096228099673819272

36. Fernandez R, Fernandez G (2009) Validating the Bland-Altman method of agreement. Annual Conference of Western Users of SAS Software. California, USA, San Jose, pp 1-17

37. Montenij LJ, Buhre WF, Jansen JR, Kruitwagen CL, De Waal EE (2016) Methodology of method comparison studies evaluating the validity of cardiac output monitors: a stepwise approach and checklist. Br J Anaesth 116:750-758. https://doi.org/10. 1093/bja/aew094

38. Giavarina D (2015) Understanding Bland Altman analysis. Biochem Med 25:141-151. https://doi.org/10.11613/bm.2015.015

39. Pottel H (2015) Critical review of method comparison studies for the evaluation of estimating glomerular filtration rate equations. Int J Nephrology and Kidney Fail 1:1-7. https://doi.org/ $10.16966 / 2380-5498.102$

40. Hopkins WG (2000) Measures of reliability in sports medicine and science. Sports Med 30:1-15. https://doi.org/10.2165/00007256200030010-00001

41. Tan R, Pauws SC, van Loon E, Smits V, Lopriore E, Te Pas AB (2018) Correlation and interchangeability of venous and capillary blood gases in non-critically ill neonates. Front Pediatr 6:89. https://doi.org/10.3389/fped.2018.00089

42. Bor-Seng-Shu E, Kita WS, Figueiredo EG, Paiva WS, Fonoff ET, Teixeira MJ, Panerai RB (2012) Cerebral hemodynamics: concepts of clinical importance. Arq Neuropsiquiatr 70:357365. https://doi.org/10.1590/S0004-282X2012000500010

43. Johnston AJ, Steiner LA, Gupta AK, Menon DK (2003) Cerebral oxygen vasoreactivity and cerebral tissue oxygen reactivity. Br J Anaesth 90:774-786. https://doi.org/10.1093/bja/aeg104

Publisher's Note Springer Nature remains neutral with regard to jurisdictional claims in published maps and institutional affiliations. 